\title{
EDITORIAL
}

\section{O processo de internacionalização na Pós-Graduação em Serviço Social no Brasil}

\author{
The process of internationalizacion in Postgraduate in Social Work in Brazil \\ JANE CRUZ PRATES (1) \\ Pontifícia Universidade Católica do Rio Grande do Sul (PUCRS), Porto Alegre, RS, Brasil.
}

quadro de profundas modificações e acirramento de desigualdades pelo qual tem passado a sociedade brasileira conforma um contexto histórico que exige novas respostas profissionais e requer o aprimoramento dos processos de formação e trabalho profissional, onde se incluem as experiências propiciadas pelos processos de internacionalização.

Por outro lado, a austeridade implementada pelo governo brasileiro para o enfrentamento da crise econômica, em especial a partir de 2016, com a aprovação da Emenda Constitucional no 95, que congela os investimentos orçamentários relativos a despesas correntes por 20 anos, tem impacto significativo na política de Educação e no financiamento de processos desse tipo, em que pese o reconhecimento quanto à importância cada vez maior desses intercâmbios.

O amadurecimento do Serviço Social, como profissão e área de conhecimento reconhecida pela Coordenação de Aperfeiçoamento de Pessoal de Nível Superior (Capes) desde 2005, tem sido de fundamental importância para o fortalecimento da área, que tem no desenvolvimento da Pós-Graduação um de seus determinantes centrais.

Contudo é importante assegurar ao Serviço Social a consolidação sistemática e progressiva desse processo, a partir da absorção pelo conjunto da categoria dos desafios impostos pelo tempo presente, marcado pela agudização e complexificação das refrações da questão social, seu objeto de trabalho. Nessa direção é fundamental decifrar necessidades e processos para que continue se afirmando como profissão necessária na contemporaneidade. Os processos de violação de diretos e interdições de toda a ordem, que marcam o contexto internacional, e particularmente o brasileiro, têm evidenciado contradições que, embora cada vez mais presentes, se mascaram e naturalizam, como parte da ideologia neoliberal, exigindo o adensamento de estratégias de análise e intervenção mais substantivas, onde se inclui as cooperações e intercâmbios científicos e culturais e as articulações de experiências exitosas nacionais e internacionais.

Ao Serviço Social impõe-se o desafio de fortalecer a sua identidade, no tensionamento das relações na esfera da produção e da reprodução social, espaço no qual se situa o seu trabalho. Sem dúvida, são questões que traduzem exigências e requisições ao trabalho do Assistente Social ao mesmo tempo em que sinalizam novos espaços ocupacionais, que reeditam dilemas éticos presentes nas tensões historicamente enraizadas na constituição da profissão e nas estratégias de respostas à questão social (IAMAMOTO, 2005). Como bem destaca lamamoto (2008, p. 49-50):

O capitalismo não só repete contradições históricas mas transforma-se e desagregase reproduzindo não só relações e meios de produção, capilariza-se transformando toda a sociedade em lugar da reprodução de suas relações sociais, todo o espaço se transforma em espaço de poder. 
A autora destaca a relevância para a formação e o trabalho profissional do assistente social o aprofundamento do debate e o rigoroso trato das múltiplas expressões da questão social e do que precisa ser enfrentado "na defesa dos direitos sociais universais e da esfera pública, recriando a sociedade e, nela, a profissão" (IAMAMOTO, 2008, p. 10).

Para dar conta disso enfatiza a necessidade de análise da questão social e ressalta que essa análise

[...] é indissociável das configurações assumidas pelo trabalho, e encontra-se necessariamente situada em uma arena de disputas entre projetos societários, informados por distintos interesses de classe acerca de concepções e propostas para condução das políticas econômicas e sociais (IAMAMOTO, 2008, p. 10).

Nesta perspectiva, o projeto conservador apresenta a questão social de modo reduzido, negando o antagonismo de classes e atribuindo esses processos a formas arcaicas de gestão o que poderia ser solucionado a partir de uma "'gestão humanizada' como se fosse admissível" um pouco menos de exploração, de trabalho infantil, de abuso ou de violação de direitos. Como contraponto, tendo em vista a teoria crítica, a questão social "é indissociável do processo de acumulação e dos efeitos que produz sobre o conjunto da classe trabalhadora" (IAMAMOTO, 2008, p. 11).

Portanto é fundamental desocultar os componentes materiais da riqueza, ou seja,a natureza do valor de troca e os fetichismos que o acompanham, não os destituindo de sua historicidade. Logo, destaca a autora, a partir de Marx, pensar o trabalho e a questão social no modo de produção capitalista significa reconhecer dois aspectos fundamentais que o caracterizam: a mercadoria é o caráter predominante e determinante dos produtos; a mais-valia (exploração/lucro) é a finalidade direta e o móvel determinante da produção (IAMAMOTO, 2008, p. 13).

Os processos universais, em especial aqueles que decorrem das contradições entre capital e trabalho são vivenciados por diferentes países, seja em termos de desigualdades ou de formas de resistência que podem apresentar elementos comuns que os aproximem, para além de suas particularidades, o que pode, via intercâmbio de experiências internacionais, ser apropriado pelos parceiros em cooperação (PRATES; CARRARO, 2018).

No que concerne a diversidade cultural e o interculturalismo, entende-se que a diversidade cultural é reconhecida pela Convenção da UNESCO, desde 2001, como característica inerente a humanidade e como patrimônio comum. A convenção para a proteção e a promoção das expressões culturais passa a conciliar duas visões: do universalismo, defesa de valores como a paz, a solidariedade, a justiça e os direitos humanos; e do particularismo, liberdade de cada um expressar sua cultura e fazer suas escolhas. A finalidade é de que, a partir do intercâmbio, as culturas possam enriquecer-se mutuamente (FONTES, 2013).

A implantação desses processos exige ações interdisciplinares e transdisciplinares, dada a sua complexidade e as múltiplas determinações que precisam ser reconhecidas nas análises e as proposições para que logrem efetividade. Contudo, a tradição de nossas formações é disciplinar, logo, a materialização de efetivas ações interdisciplinares e transdisciplinares requer a superação de alguns limites, dentre os quais se destaca a histórica hierarquização das profissões, reiterada pela divisão social e técnica do trabalho. O processo de educar para o interculturalismo ou contemplando o interculturalismo não ocorre sem o atravessamento de contradições. São exemplos desse processo a aculturação sofrida por comunidades tradicionais.

O debate acerca do multiculturalismo ou interculturalismo inclui questões relacionadas não só a cultura, mas requer o reconhecimento efetivo da diversidade, logo, em um país marcado por profundas desigualdades como o Brasil, não é suficiente debater a particularidade de cada cultura. É preciso situá-las no espaço social e nas relações também desiguais de poder a que estão sujeitas (FONTES, 2013).

Uma formação intercultural exige antes de tudo a valorização de identidades diversas, o reconhecimento de que algumas foram e são desvalorizadas, mesmo que de modo velado e investir na possibilidade de diálogo, portanto o processo pedagógico de participação é central. Como já alertava o grande educador Paulo Freire sobre o diálogo entre sujeitos singulares e coletivos de que não é possível dialogar se vejo no outro um "isso ou qquilo" e não um outro eu (FREIRE, 1997, p. 136). 
Os temas da internacionalização e do intercâmbio entre culturas, realizado de modo crítico, à luz da totalidade e das contradições que os condicionam é fundamental no âmbito da pós-graduação, dadas as exigências do tempo presente e das possibilidades que esses processos aportam para a ampliação da formação e da produção de conhecimentos, se efetivamente se pautarem em relações horizontais de troca, respeito, valorização de saberes diversos, reconhecimento da diversidade e postura de solidariedade.

A Pós-Graduação em Serviço Social "vem contribuindo significativamente para a maioridade do Serviço Social no Brasil no domínio da elaboração teórica", bem como para a qualificação docente, a formação de pesquisadores e profissionais em todo o País, "uma intelectualidade que passou a ser o vetor elementar a subsidiar o mercado de bens simbólicos da profissão" (NETTO, 1999 apud YAZBEK; SILVA, 2005, p. 40).

Porém, é preciso identificarmos o modo como a nossa pós-graduação vem se inserindo em processos de internacionalização no tempo presente para subsidiar avaliações e o debate profissional coletivo sobre alternativas de potencializá-la a partir de interfaces e produções conjuntas, o que já vem se efetivando via programas como Casadinhos, PROCADS, entre outros, que tem contribuído sobremaneira para o fortalecimento conjunto de muitos Programas de Pós-Graduação, embora os resultados desses processos careçam de mais visibilidade, especialmente, quanto aos impactos desses processos.

A importância da investigação e de uma formação que privilegie os intercâmbios interculturais, a capacidade investigativa em âmbito nacional e internacional para o fortalecimento do Serviço Social como profissão e para o aprimoramento do trabalho do assistente social é fundamental, pois a partir desses processos produzimos conhecimentos sobre como se constituem os condicionantes de nosso trabalho, as condições em que é realizado, os processos e resultados que desencadeiam, dando visibilidade a suas contribuições para a sociedade. Não é por outra razão que, as Diretrizes Curriculares que orientam a formação e o trabalho profissional no Brasil (ABEPSS, 1996) destacam a pesquisa como um dos elementos que lhe são transversais (PRATES, 2009).

Contudo, a pesquisa em âmbito internacional exige, para além de questões básicas como o domínio do idioma ou o uso de tecnologias que possam auxiliar no acesso à linguagem e aos contatos com o outro, o enfrentamento do desafio de conviver com o estranho, com aquilo que nem sempre nos identificamos. É preciso estar aberto a acolher o desconhecido, a compatibilizar linguagens, referenciais teóricos, conceitos, modos de trabalhar conjuntamente, entre outros processos que requerem tempo e disponibilidade. A constituição de redes de trabalho integrado entre Instituições de Ensino Superior (IES) brasileiras e estrangeiras favorece o amadurecimento de processos grupais e a constituição do espírito de corpo, fundamental para que o grupo comece a construir uma identidade coletiva, mesmo que diversa, especialmente quando se tem a oportunidade de realizar pesquisas consecutivas, estreitando relações de cooperação. Somente para fins de exemplo, em experiência de internacionalização realizada apenas com países latino-americanos fomos surpreendidos pela diversidade de concepções relativas a um mesmo processo, no caso a universalização. Para países como Cuba e Chile, é necessário a garantia efetiva da cobertura total, com prazos de atendimento curtos e bem definidos, para que uma política seja considerada universal, somente a possibilidade de acesso a todos os usuários da política, concepção adotada no Brasil, não a configura como universal. A compatibilização de conceitos, caracterizações, apropriações das particularidades de cada realidade é fundamental para que o diálogo ocorra e, posteriormente, se efetive o intercâmbio de conhecimentos e a realização de produções conjuntas.

A partir da década de 1990, a internacionalização nas IES passa a ser incluída como um componente central às principais funções da educação superior - ensino, pesquisa e extensão -, decorrente da mundialização do conhecimento, que vem sendo fortalecida e ampliada com a integração entre instituições de ensino superior de diversos países no mundo, sendo, também resultado da ampliação de inovações tecnológicas de informação e comunicação. Os contatos e reuniões utilizando-se de recursos como vídeoconferências, alternadas com encontros presenciais, reduzindo a distância entre os parceiros e os custos do processo, são alguns dos exemplos.

Os níveis de internacionalização dos Programas de Pós-Graduação (PPGs) podem ser identificados a partir de um conjunto de indicadores entre os quais: acordos e convênios formalizados; atração de 
alunos estrangeiros para doutorados-sanduíche; alunos em IES estrangeiras para realização de doutoradossanduíche; atração de estrangeiros para pós-doutorados ou estágio sênior pós-doutoral de docentes; docentes em estágio pós-doutoral e/ou estágio-sênior no exterior; docentes do corpo permanente e colaboradores com participação em PPGs no exterior. São, ainda, indicadores de processos de internacionalização, a visita de professores estrangeiros; a participação de docentes permanentes em diretorias de associações científicas ou de agências de fomento internacionais; a emissão de pareceres ad hoc para revistas internacionais; a emissão de pareceres sobre comunicações científicas em eventos internacionais; participação em comitês editoriais e em editoria de periódicos de circulação internacional. Do mesmo modo, constituem-se como indicadores de internacionalização as iniciativas de cooperação e intercâmbio internacional dos grupos de pesquisa; participação em projetos de pesquisa internacionais; financiamento internacional para atividades da pós-graduação; participação de docentes em eventos científicos internacionais, como convidados ou participantes/ouvintes, realizados no Brasil e/ou no exterior; realização de eventos conjuntos; efetivação de processos de cotutela ${ }^{1}$ e dupla titulação; produção bibliográfica docente e discente internacional; produção de publicações conjuntas; bancas e outras atividades acadêmicas concretizadas pelo PPG com a participação de pesquisadores estrangeiros, dentre outros processos similares (PRATES; CARRARO, 2018).

\section{O processo de internacionalização na área do Serviço Social}

Em estudo realizado no período de 2015-2016 pelo Grupo de Estudos sobre Teoria Marxiana, Ensino e Políticas Públicas (GTEMPP) em parceria com a PUCSP e a Associação Brasileira de Ensino e Pesquisa em Serviço Social (ABEPSS), efetivou-se um levantamento sobre os processos de internacionalização nos PPGs da área no Brasil, com vistas a identificar os níveis de internacionalização e estimular a solidariedade entre os programas da área nessa direção. $O$ estudo foi realizado a partir do encaminhamento de um instrumento de coleta, do tipo questionário, com questões abertas e fechadas a todos os coordenadores dos cursos de mestrado e doutorado, no segundo semestre de 2015 , com previsão de conclusão para o primeiro semestre de 2016. Porém, em razão de intensos processos de precarização, instabilidade econômica e política no País, greves, cortes de recursos, excesso de demandas, os coordenadores solicitaram o protelamento do prazo por diversas vezes e, apesar de vários contatos diretos terem sido realizados pelos integrantes da equipe de pesquisa solicitando a devolução obtivemos apenas o retorno de 13 instrumentos (de um total de 31 PPGs em atividade na ocasião). Depois de longo período de espera, optou-se por buscar na Plataforma Sucupira os dados relativos aos restantes 18 PPGs, e verificou-se que dados mais detalhados sobre o tema não eram disponibilizados, nem mesmo na plataforma.

Realizou-se o levantamento buscando identificar não só convênios formalmente executados pelos PPGs com países estrangeiros, mas identificar os principais países com os quais a área do Serviço Social mantém interfaces e os temas trabalhados nessas parcerias. Procurou-se também constatar a inserção internacional de docentes e discentes, a atração de alunos estrangeiros para a realização de intercâmbios, a busca de estrangeiros por estágios pós-doutorais, a mobilidade acadêmica internacional de alunos dos Programas, a efetivação de processos de cotutela e dupla titulação, além de eventos, bancas e outras atividades acadêmicas desenvolvidas com a participação de pesquisadores estrangeiros. Levantou-se, ainda, docentes dos PPGs que participaram como convidados de eventos internacionais no Brasil e no exterior, além da produção bibliográfica internacional de docentes e discentes. Esses foram basicamente os indicadores utilizados para verificar os níveis de internacionalização que compuseram as questões apresentadas no instrumento de pesquisa encaminhado aos pares.

A exigência de internacionalização começa a ser demandada em PPGs com avaliação ${ }^{2}$ conceito 5 junto à Capes, não é exigida dos Programas 3 e 4, mas é condição necessária para os que se encontram nos estratos 6 e 7. Esses naturalmente são os que apresentam os maiores níveis de internacionalização. O levantamento mostrou que somente aqueles avaliados nesse estrato contemplavam o conjunto dos indicadores relativos ao processo de internacionalização, embora todos tenham entre seus parceiros nesses processos, especialmente 
a partir de Casadinhos e Programas de Cooperação Acadêmica (Procads), Programas de nota 4 e 5 e, em alguns casos, de nota 3. Aqueles que têm nota 6 são os mais antigos e, portanto, dispõem de uma estrutura, uma produção e um quadro de pesquisadores mais consolidado, o que favorece a internacionalização, a busca por financiamento internacional, ou mesmo o apoio de agências nacionais e internacionais na consolidação de processos mais complexos e onerosos, cujas exigências são maiores.

Frisa-se que os processos de internacionalização da área do Serviço Social precisam considerar, em sua análise, o tempo histórico de emergência dos cursos de pós-graduação. Em 1972 foi criado o primeiro curso de pós-graduação em Serviço Social na Pontifícia Universidade Católica de São Paulo (PUC-SP), ainda em 1972 o da Pontifícia Universidade Católica do Rio de Janeiro (PUC-RJ); 1976 na Universidade Federal do Rio de Janeiro (UFRJ); 1977 na Pontifícia Universidade Católica do Rio Grande do Sul (PUCRS), 1978 na Universidade Federal da Paraíba (UFPB), 1979 na Universidade Federal de Pernambuco (UFPE). Em 1980 a Pontifícia Universidade Católica de São Paulo cria o primeiro curso de doutorado. Com o fim da ditadura foram criados mais dois cursos de mestrado: em 1991 na Universidade Nacional de Brasília (UNB), e em 1993 na Universidade Estadual de São Paulo (UNESP-Franca), e um curso de doutorado na Universidade Federal do Rio de Janeiro (KAMEYAMA, 1998).

Importante referir que a PUC-SP, cujo doutorado foi o primeiro da América Latina, inaugurou a implantação de processos de internacionalização no Serviço Social, sendo o PPGs responsável e assessor na instituição e consolidação da pós-graduação em Portugal e na Argentina e, no conjunto dos programas da área no País. Constitui-se em uma referência nacional e internacional, com produção nacional e estrangeira qualificada em estratos superiores e no PPG que possui maior volume de mobilidade docente e discente internacional e de processos de cotutela. Os processos de cotutela e dupla titulação registrados na Plataforma Sucupira e informados nos instrumentos de coleta, além da PUC-SP ocorrem apenas em mais dois PPGs da área, em parceria com a França, a Itália e Portugal, consolidando, consequentemente, convênios bilaterais. A PUC-RS apresenta a particularidade de seu Programa de Doutorado ter sido implantado em parceria com a Universidade de Kassel, Alemanha, através de um Procad, logo, esse programa tem uma conformação internacional desde a sua origem.

Os países com os quais os PPGs têm maior volume de convênios internacionais são respectivamente: Argentina (8), França (6), Portugal e Espanha (4), EUA, Inglaterra, México, Chile, Venezuela, Cuba e Itália (3 cada país), Canadá e Alemanha (2 cada), e com Haiti, China, Peru e Moçambique apenas 1 PPG possui convênio formalizado. Isso não significa que existam pesquisas em andamento atualmente com todos esses países. Considerou-se para fins de pesquisa, desses dados, apenas os convênios firmados, a partir dos quais foram gerados ou estão em curso missões de trabalho, mobilidades (docentes e discentes), pesquisas conjuntas com financiamento de agências de fomento nacionais e estrangeiras, intercâmbios de pesquisa efetivos de algum tipo de cooperação científica, não apenas a formalização do contrato.

Os PPGs que informaram sobre pesquisas internacionais em andamento na ocasião da coleta foram apenas 8, desenvolvidos em parceria com França, Inglaterra, China, Colômbia, Uruguai, Argentina, Paraguai, Cuba, Chile, Portugal, Peru, Venezuela e Haiti. Os temas abordados nos estudos versavam sobre: políticas sociais, proteção social, sistemas de seguridade social, formação, pós-graduação em Serviço Social, saúde na fronteira, movimentos sociais e cidadania, risco social e envelhecimento, participação social de migrantes, desenvolvimento comparativo entre países de três continentes, reforma do Estado de Bem-Estar, transferência de renda, dilemas ético-políticos do trabalho do assistente social, saúde e doença. Salienta-se que vários desses assuntos compõem os eixos temáticos prioritários pesquisados pelo conjunto da área. Os demais programas não informaram ou não dispunham de pesquisas internacionais em andamento na ocasião da coleta.

Em relação aos alunos oriundos de outros países que procuram os PPGs da área do Serviço Social são provenientes de Moçambique, Haiti, Angola, Guiné Bissau, Argentina, Uruguai, Colômbia, Paraguai, Portugal, Espanha, Alemanha, França, EUA, Noruega e Japão. Ressalta-se que 1/3 desses países, são os mesmos de destino dos bolsistas brasileiros de doutorado-sanduiche no exterior, conforme consta no Gráfico 1 do Documento de Área de 2016, apresentado a seguir. 
Gráfico 1 - Países de destino dos bolsitas de doutorado sanduíche no exterior

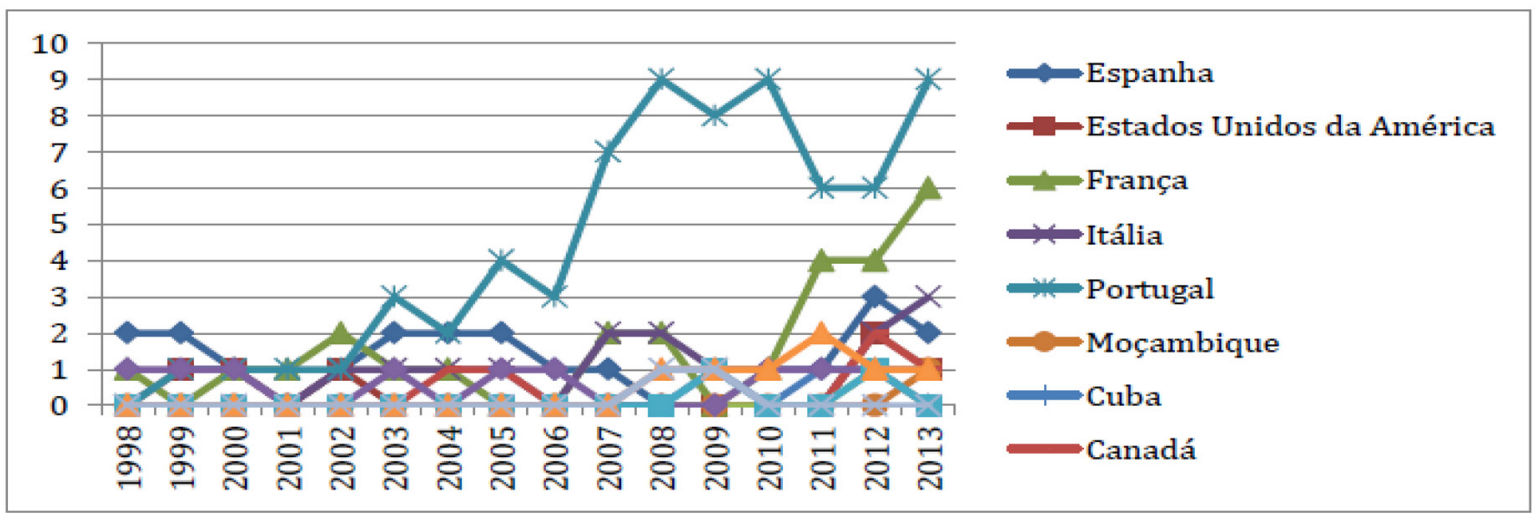

Fonte: Reprodução de Garcia, Nogueira, Forti (2016, p. 11) baseado no Documento de Área de 2016

Como se pode verificar no gráfico apresentado, o destino dos alunos brasileiros bolsistas de doutorado-sanduíche comuns ao dos alunos de outros países, compreende: Espanha, EUA, França, Portugal e Moçambique, possivelmente em função de acordos e parcerias historicamente realizados, afinidade por área de conhecimento e proximidade geográfica, o que sem dúvida merece um aprofundamento da investigação para saber melhor sobre os motivos dessas escolhas, identificando os fatores de atração. Não se pode deixar de mencionar que esses países integram a lista de destinos, com os quais o Brasil possui acordos de cooperação internacional, de alunos brasileiros e estrangeiros definida pela Capes, juntamente com a modalidade de programas disponibilizados: Alemanha, Argentina, Áustria, Bélgica, Canadá, Colômbia, Cuba, Espanha, Estados Unidos, França, Países Baixos, Israel, Itália, Japão, Noruega, Portugal, Reino Unido, Suécia, Uruguai (CAPES, 2018b).

Em relação às principais dificuldades encontradas pelos PPGs para consolidar a internacionalização, os respondentes (ressalte-se que menos de 50\% responderam ao instrumento de coleta) indicaram: escassos recursos disponíveis para estimular a participação de alunos e professores em eventos internacionais e custear a tradução de artigos para línguas estrangeiras; poucos editais que financiam processos de internacionalização e notadamente a dificuldade de domínio de línguas estrangeiras por professores e alunos, em especial a língua inglesa. Apenas programas com avaliação 3 e 4 (70\% dos que responderam ao instrumento de coleta) mencionaram que a sua preocupação básica centrou-se na organização interna do programa, na adequação de linhas e estruturas de pesquisa, disciplinas, prazos de titulação, restando pouco tempo e, por vezes, falta de condições objetivas de trabalho para os seus pesquisadores se dedicarem a processos de internacionalização mais consistentes. Soma-se a isso, a recente estruturação de planos institucionais de internacionalização e a escassa produção científica (livros, teses, dissertações, artigos) na área do Serviço Social (e outras áreas do conhecimento) sobre os processos que a conformam na educação superior (em nível de pós-graduação).

Por outro lado, verificou-se que a área possui apropriado nível de internacionalização nos estratos mais elevados, com diferencial entre os programas de pós-graduação que buscam a excelência das atividades desenvolvidas nos cursos de mestrado e doutorado mais antigos e consolidados, envolvendo a formação qualificada de docentes e pesquisadores e a produção e a circulação de conhecimentos de temas de relevância social e de interesse profissional. Historicamente e ao longo do tempo, a internacionalização ocorreu por meio de um amplo leque de interfaces com diversos países da América Latina, Europa e África, predominantemente com Argentina e França, no conjunto do País, em que pese a maior concentração em relação ao primeiro no Sul do País. Do mesmo modo, em razão da proximidade geográfica a maior interface com países como Colômbia e Venezuela, se efetiva com PPGs do Norte e Nordeste do País. Chama atenção o reduzido número de parcerias formalizadas com Portugal, em relação aos dois primeiros. Há também, um crescente número de tratativas de convênios, na sua maioria com os países mencionados, nas 
quais Portugal aparece com destaque, envolvendo programas de diferentes estratos apoiados pelos PPGs consolidados.

No que tange ao volume de bolsas para a realização de estágios pós-doutorais e estágios sênior constata-se, respectivamente, uma oscilação de crescimento e decréscimo na primeira e aumento significativo da segunda, levando em conta o período de 2010 a 2013, conforme pode ser visto no Gráfico 2 apresentado pelo Documento de Área de 2016.

Gráfico 2 - Evolução do número de bolsas de pós-doutorado e estágio sênior

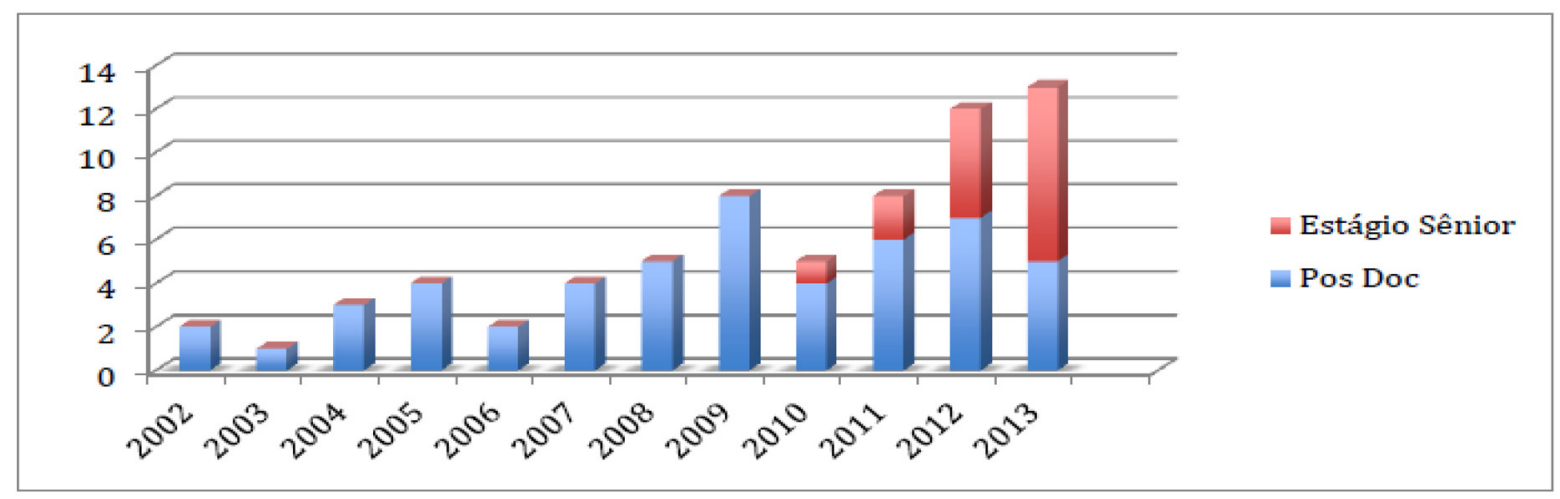

Fonte: Reprodução de Garcia, Nogueira, Forti (2016, p. 11) com base no Documento de Área de 2016.

Diante dos dados sistematizados no gráfico apresentado, considerando o período de 2010 a 2013, observa-se uma contínua evolução do número de bolsas de estágio sênior no exterior, destinadas a pesquisadores ou docentes que possuam vínculo empregatício com instituição brasileira de ensino ou pesquisa e que obtiveram doutoramento há oito anos ou mais. Isso se expressa em função do estímulo à qualificação docente via aumento da oferta de bolsas no exterior que ocorria neste período. Similarmente ocorreu com as bolsas de pós-doutorado (ou estágio pós-doutoral) no exterior, voltadas a pesquisadores ou docentes com menos de oito anos de formação doutoral e sem vínculo empregatício, apesar da oscilação entre acréscimo e declínio, mesmo que pouco expressiva.

Por fim é importante destacar que a mundialização do conhecimento e as formas como esse processo vem se configurando têm exigido dos programas de pós-graduação a ampliação de espaços de produção e disseminação de saberes, decorrentes da pesquisa, em um esforço de expandir as referências de interlocução e o intercâmbio entre os pesquisadores, ampliando as possibilidades de construção coletiva, os espaços de reflexão e troca de experiências, a democratização e a socialização do conhecimento gerado.

Por sua vez, a internacionalização é uma força motriz para solidificar a solidariedade e a articulação entre os PPGs, estimulando a composição de uma agenda temática comum e a construção de redes de pesquisadores, e condição fundamental para consolidar a excelência científica em ensino e pesquisa, e dar visibilidade à produção acadêmica. Afirma-se, também, que no caso do Serviço Social os processos de internacionalização podem contribuir para "envidar esforços no sentido de fortalecer nossa direção social estratégica, crítica, com claro posicionamento de classe e vinculada a defesa de valores emancipatórios" (ABEPSS, 2015, p. 19), em um diálogo respeitoso entre pares que contemple as diferentes construções históricas e teórico-políticas de cada país, haja vista a dissonância conceitual sobre a profissão em termos de formação e de trabalho em cada realidade. Desse modo, a internacionalização em seus processos de produção de conhecimento pode contribuir para acumular maior discussão sobre as parecenças e divergências que caracterizam o Serviço Social, bem como encontrar pontos de convergência para a construção de projetos comuns (PRATES; CARRARO, 2018).

Nessa direção, amplia-se a necessidade e o interesse por seu entendimento e aprimoramento de ações no sentido de avançar na solidificação da internacionalização. Em vista disso, as IES têm envidado esforços, 
especialmente nos últimos anos, em direção à formulação de planos institucionais de internacionalização, com estudos e análises situacionais (diagnósticos) para a definição de diretrizes, prioridades, objetivos, estratégias e ações para viabilizar a cooperação e intercâmbios internacionais entre PPGs nacionais e estrangeiros, levando em conta a viabilidade, em termos de condições e suporte institucional e contando com o apoio da Associação Brasileira de Ensino e Pesquisa em Serviço Social (ABEPSS).

Sendo assim, no Documento que orienta a Pós-Graduação no Brasil, a ABEPSS destaca em relação a internacionalização, o protagonismo da PUC de São Paulo no processo de implantação de Programas de Pós-Graduação na Argentina e em Portugal. Quanto às orientações nessa área, ainda muito incipientes, o documento apenas estimula a solidariedade entre os PPGs, o que já está previsto no documento de área da Capes. Ressalte-se que muitas orientações, tais como a interface entre Graduação e Pós-Graduação e a solidariedade entre os PPGs através de parcerias via Mestrado Interinstitucional (Mlinter), Doutorado Interinstitucional (Dinter), Procads, entre outras formas de interface, que já constavam no documento de área da Capes e eram valorizados no processo de avaliação, mesmo antes da promulgação do documento.

Destacamos que a sistematização de um documento orientando a Pós-Graduação e não apontando diretrizes, foi uma importante contribuição da ABEPSS, especialmente para que o debate sobre esses temas fossem ampliados. Sem dúvida, o contexto agravado de conservadorismo exige novas avaliações e planejamento de estratégias para o enfrentamento coletivo da área aos desafios que não são poucos, especialmente em tempos de recessão.

Por fim, é preciso que se enfrente alguns debates polêmicos que têm surgido em PPGs que têm outras áreas trabalhando em interface com o Serviço Social a partir de Programas de Política Social. Não há dúvidas que o projeto ético-político dá a direção como conjunto de valores à profissão e à área, mas o respaldo no Código de Ética e na Lei de Regulamentação não podem ser exigidos às demais profissões que também se formam nessa área, embora a predominância seja de assistentes sociais. $O$ diálogo com a área e com os valores de seu projeto ético-político, no entanto, são requisitos fundamentais aqueles que nela se inserem para a obtenção do título de mestres e doutores nessa área. Porém, a área abarca Programas de Pós-Graduação em Serviço Social e Programas de Pós-Graduação em Políticas Sociais, com variações para Políticas Públicas e Políticas de Desenvolvimento. O título obtido por um aluno com pós-graduação strito senso em política social será de mestre em políticas sociais e não em Serviço Social, embora o Programa esteja vinculado a essa área de conhecimento. A própria exigência em termos da formação dos docentes se difere para um Programa de Pós-Graduação em Serviço Social que exige a titulação de $60 \%$ de seus professores na área, enquanto nos Programas de Pós-Graduação em Políticas Sociais e suas variações, essa exigência cai para $40 \%$. A área das políticas, por sua natureza, é interdisciplinar, embora a abordagem realizada a partir da área do Serviço Social tenha suas particularidades que se direcionam por seu projeto ético-político, mas nesses Programas o trato do Serviço Social como tal, enquanto profissão e área do conhecimento, necessariamente não precisa ser central, ao passo que as políticas sociais têm centralidade. Nos Programas de Pós-Graduação em Serviço Social, em princípio, o Serviço Social precisa ser central, a garantia de um adensamento sobre os seus fundamentos é essencial, embora a necessária relação com as políticas sociais seja uma de suas particularidades. Temos a clareza do quão polêmicos são esses argumentos aportados, contudo, o que se verifica é que nem mesmo nos cursos cuja formação é em Serviço Social há garantia de uma formação mais adensada, com disciplinas obrigatórias sobre fundamentos de Serviço Social, de modo a garantir que um profissional de outra área, para obter o título de mestre ou doutor em Serviço Social aproprie-se obrigatoriamente desses conteúdos. Em relação a esses aspectos, também a troca de experiências internacionais relativas a orientações, regulações, pautas prioritárias da área, formas de organização, entre outras, pode ser profícua (PRATES, 2016).

Portanto, a realização de novos estudos, pesquisas e sistematizações teórico-práticas sobre as experiências e o conjunto de processos que compõem a internacionalização, seus resultados, limites e possibilidades, especialmente relacionadas à área do Serviço Social, dada a escassa produção de conhecimento sobre o tema, são de extrema relevância para a área.

O presente volume da revista Textos \& Contextos; está subdividido em 4 eixos, o primeiro intitulado Conjuntura, pensamento político e método, articula quatro artigos. Abrindo a revista e, portanto, com 
tradução para língua inglesa, apresenta-se o artigo "Brasil: as alterações institucionais no período recente e o novo governo", que debate os impactos de medidas de austeridade no contexto contemporâneo brasileiro e as repercussões de medidas implementadas nos governos Temer e Bolsonaro, que redefinem o lugar do Estado na economia e na sociedade. Dando prosseguimento, o segundo artigo "Conjuntura brasileira no século XXI: o nó da nossa solidão", na mesma direção aborda os principais elementos que determinam a conjuntura brasileira atual, articulando a dinâmica econômica com elementos coetâneos, que dão visibilidade à particularidade desses processos no Brasil. $\mathrm{O}$ terceiro artigo, intitulado "A democratização na evolução do pensamento de George Lukács", aborda a política em Lukács como uma dimensão da práxis, processo de democratização radicalmente socialista e como postura filosófica que tem na dialética marxiana a sua base de sustentação. O último artigo do primeiro eixo, "O método hermenêutico-dialético aplicado às ciências sociais: uma análise sobre sua utilização para o tráfico de drogas", aborda a aplicabilidade desse método para interpretar a complexidade "inerente ao fenômeno, social, econômico, político e territorial, tráfico de drogas", conforme ressaltam os autores.

O segundo eixo, intitulado Serviço Social no Brasil e em Cuba é composto por três artigos, o primeiro, "Tendências atuais no ensino dos fundamentos do Serviço Social", é fruto de pesquisa de pós-doutoramento sobre o tema, realizada a partir de análise documental de Projetos Pedagógicos em Unidades de Formação Acadêmica (UFAs) brasileiras que mostram o caráter dialético e ontológico, de cariz marxiano, como predominante no ensino dos fundamentos. O segundo, intitulado "Implicações para o Serviço Social no contexto da reconfiguração das políticas sociais", traz os desafios impostos à profissão no cenário atual. Já o último artigo que completa esse eixo, intitulado "Trabalho Social cubano e tendências teóricas atuais", aporta uma recuperação da história cubana e as inspirações teórico políticas que têm orientado o serviço social cubano nos últimos 25 anos, além das tendências, elementos constituintes e teses centrais, que conformam a área naquele país e, por fim, debate, ainda, os limites e possibilidades para a instituição do serviço social como curso de nível superior em Cuba.

O terceiro eixo, Seguridade, acolhimento e pobreza, contempla quatro artigos, o primeiro "Visão de jovens pais e mães sobre medidas e acolhimento institucional de seus filhos", apresenta resultado de pesquisa e buscou identificar os elementos fundamentais que interferiram na reprodução social da família e que comprometeram a proteção e o cuidado para com seus filhos. O segundo artigo intitulado "Envelhecimento, sustentabilidade e reforma do Sistema de Seguridade Social brasileiro: um novo desafio demográfico para uma velha questão política", aporta subsídios para uma análise das diferentes posições políticas acerca da sustentabilidade do Sistema de Seguridade Social brasileiro. O terceiro artigo, "O acolhimento em saúde no espaço da rua: estratégias de cuidado do consultório na rua", apresenta resultados obtidos a partir de pesquisa de mestrado sobre o tema do acolhimento em saúde no espaço da rua, a partir das percepções dos sujeitos trabalhadores e usuários do serviço. O quarto e último artigo desse eixo intitula-se "A estratégia hegemônica de enfrentamento à pobreza no Brasil redemocratizado" e debate o alinhamento nacional ao processo de internacionalização do combate à pobreza que "promove a naturalização e gestão da barbárie", segundo a autora, visto que lavra, por um lado, a aceitação da condição de pobreza e por outro a negação das condições que a determinam.

O quarto e último eixo, intitulado Questão Social e Política de Assistência Social, é também composto por quatro artigo, o primeiro "Activación y 'cuestión social' una apuesta regresiva en el Uruguay Progresista", debate a concepção de questão social e um sistema tido como "típico ideal" e a partir dele as propostas contidas na Política de Assistência Social desenvolvidas pelo Ministério do Desenvolvimento Social do Uruguai. O segundo artigo intitulado "Desigualdade e diversidade, o fator amazônico no contexto da Política de Assistência Social no Pará", debate a centralidade do território na materialização da Política para além do binômio desigualdade/diversidade. O terceiro artigo que conforma o eixo quatro, se intitula "O Plano Brasil sem Miséria e a modernização conservadora da Política de Assistência Social" e apresenta parte dos resultados da pesquisa de doutorado da autora que estudou o movimento de modernização da política de assistência social durante os governos de Lula e Dilma à luz da crítica marxista do desenvolvimento capitalista dependente e periférico no Brasil. E finalizando o eixo e a edição da revista, o último artigo apresentado, "A Assistência Social no município de Campinas (SP) e as relações de trabalho no terceiro setor", analisa 
as condições de trabalho em instituições do terceiro setor, que executam serviços de assistência social no município de Campinas, à luz do avanço do neoliberalismo e da reestruturação produtiva.

Espera-se que as produções apresentadas na revista possam constituir-se com fontes de consulta para pesquisadores, estudantes e profissionais, e instigar novos debates e novas investigações.

Deseja-se a todos e todas uma boa leitura.

\section{Referências}

ABEPSS. Contribuição da ABEPSS para o fortalecimento dos Programas de Pós-Graduação em Serviço Social no Brasil. Rio de Janeiro: ABEPSS, 2015. Disponível em: http://www.abepss.org.br/arquivos/anexos/contribuicao-da-abepss-para-ofortalecimento-dos-programas--de-pos-revisto-201703241351072223440.pdf. Acesso em: 05 jul. 2018. https://doi.org/ 10.22422/temporalis.2017v17n33p257-283

ABEPSS. Diretrizes gerais para o Curso de Serviço Social. Rio de Janeiro: ABEPSS, 1996.

ABERBACH, Graciela et al. Algo esta sucediendo y tiene que ver com... entre la perplejidade y la incertidumbre. "Quiénes son los estudiantes de TSI 2007? Cuáles sons us características socioeconômicas y culturales presentan"? Como inciden en su processo de aprendizaje? In: CONGRESO NACIONAL DE TRABAJO SOCIAL Y ENCUENTRO LATINOAMERICANO DE DOCENTES, PROFESIONALES Y ESTUDIANTES DE TRABAJO SOCIAL, 2., 2007, Tandil. Anais [...]. [S. I.: s. n]: 2007. https://doi.org/10.35537/10915/59220

CAPES. Coordenação de Aperfeiçoamento de Pessoal de Nível Superior. Portaria no 186, de 29 de setembro de 2017. Regulamento que estabelece as normas para as modalidades de bolsa no exterior, aplicável às ações fomentadas pela Diretoria de Relações Internacionais da Capes. Brasília, DF: Capes, 2017a. Disponível em: https://www.capes.gov.br/ images/stories/download/legislacao/04102017-PORTARIA-N-186-DE-29-DE-SETEMBRO-DE-2017.pdf. Acesso em: 05 jul. 2018. https://doi.org/10.4000/books.iheal.1748

CAPES. Coordenação de Aperfeiçoamento de Pessoal de Nível Superior. Portaria no 59, de 21 de março de 2017. Dispõe sobre o regulamento da Avaliação Quadrienal. Brasília, DF: Capes, 2017b. Disponível em: http://capes.gov.br/images/ stories/download/avaliacao/27032017-Portaria-59-21-03-2017-Regulamento-da-Avaliacao-Quadrienal.pdf. Acesso em: 05 jul. 2018. https://doi.org/10.5585/eccos.n30.3704

CAPES. Coordenação de Aperfeiçoamento de Pessoal de Nível Superior. Portaria no 8, de 12 de janeiro de 2018. Aprova Regulamento Geral para Projetos Internacionais, que estabelece normas referentes a programas de cooperação acadêmica internacional fomentados pela Diretoria de Relações Internacionais da Capes. Brasília, DF: Capes, 2018a. Disponível em: https://www.capes.gov.br/images/stories/download/legislacao/17012018-PORTARIA-N-8-DE-12-DE-JANEIRO-DE-2018-V. pdf. Acesso em: 05 jul. 2018. https://doi.org/10.26512/2016.03.t.22338

CAPES. Coordenação de Aperfeiçoamento de Pessoal de Nível Superior. Doutorado Sanduíche: programas por destino. Brasília, DF: Capes, 2018b. Disponível em: http://www.capes.gov.br/bolsas-e-auxilios-internacionais/modalidadesde-bolsas/modalidade/doutorado-sanduiche. Acesso em: 05 de julho de 2018. https://doi.org/10.4000/books.iheal. 1748

CAPES. Coordenação de Aperfeiçoamento de Pessoal de Nível Superior. Plataforma Sucupira. Informações do programa. Brasília, DF: Capes. Disponível em: https://sucupira.capes.gov.br/sucupira/public/informacoes_programa/ informacoesPrograma.jsf. Acesso em: 21 jun. 2016. https://doi.org/10.26512/2016.03.t.22338

CARVALHO, Denise B. B. de; SILVA, Maria Ozanira da S. e (org.). Serviço Social, Pós-Graduação e produção do conhecimento no Brasil. São Paulo: Cortez, 2005.

FREIRE, Paulo. Criando métodos de pesquisa alternativa: aprendendo a fazê-la melhor através da ação. In: BRANDÃO, Carlos Rodrigues (org.). Pesquisa participante. 8. ed. São Paulo: Brasiliense, 1990.

GARCIA, Maria Lúcia Teixeira; NOGUEIRA, Vera Maria Ribeiro. FORTI, Valéria Lucília. Documento de Área Serviço Social. Brasília, DF: Capes, 2016. Disponível em: http://capes.gov.br/images/documentos/Documentos_de_area_2017/32_SSOC_ docarea_2016.pdf. Acesso em: 05 jul. 2018.

IAMAMOTO, M. V. O debate contemporâneo do Serviço Social e a ética profissional. In: BONETTI, D. A. et al. Serviço Social e ética: convite a uma nova práxis. 6. ed. São Paulo: Cortez, 2005. p. 87-104. 
IAMAMOTO, M.; CARVALHO, R. Relações Sociais e Serviço Social no Brasil: esboço de uma interpretação históricometodológica. São Paulo: Cortez; Lima: CELATS, 1982. p. 29-105.

IAMAMOTO, Marilda Villela. Serviço Social em Tempo de Capital Fetiche: capital financeiro, trabalho e questão social. 2. ed. São Paulo: Cortez, 2008.

KAMEYAMA, Nobuco. A trajetória da produção de conhecimentos em Serviço Social: avanços e tendências (1975-1997). Caderno ABESS, São Paulo, n. 8, nov. 1998.

MARRARA, Thiago. Internacionalização da Pós-Graduação: objetivos, formas e avaliação. Revista Brasileira de Pós-Graduação, Brasília, DF, v. 4, n. 8, p. 45-262, dez. 2007. Disponível em: http://ojs.rbpg.capes.gov.br/index.php/ rbpg/article/view/132/126. Acesso em: 05 jul. 2018. https://doi.org/10.21713/2358-2332.2014.v11.521

PRATES, J. Cruz; CARRARO, Gissele. Os processos de internacionalização da área do Serviço Social na formação pós-graduada. In: ENPESS, 16., 2018, Brasília, DF. Anais [...]. Brasília, DF: ABEPSS, 2018.

PRATES, Jane Cruz. Relatório de Pós-Doutorado: A Direção da Pós-Graduação em Serviço Social no Brasil e a importância dos Núcleos e Grupos de Pesquisa para a constituição desse processo. São Paulo: PPGSS, PUC/SP, 2016. https://doi. org/10.21041/conpat2019/v2pat302

PRATES, Jane C. La conjuntura y los desafíos para la enseñanza y la investigación En el enfrentamiento a la cuestión social. Revista Regional de Trabajo Social, Montevideo, n. 45, 2009. https://doi.org/10.2307/j.ctv6hp3gc.14

YAZBEK, Maria Carmelita; SILVA, Ozanira da Silva e. Das origens à atualidade da profissão: a construção da Pós-Graduação em Serviço Social no Brasil. In: CARVALHO, Denise B. B. de; SILVA, Maria Ozanira da S. e (org.). Serviço Social, Pós-Graduação e produção do conhecimento no Brasil. São Paulo: Cortez, 2005. https://doi.org/10.20396/sss. v14i1.8638906

YAZBEK, M. C. Os fundamentos do Serviço Social na contemporaneidade. Cadernos Capacitação em Serviço Social e política social, mod. 04. Brasília: CEAD, 2000, p.19-34.

\section{Notas}

${ }^{1}$ A título de explicação do que compreende a cotutela e sua diferença com a coorientação: "A cotutela se distingue da coorientação, principalmente porque, no primeiro caso, o aluno de pós-graduação obtém um diploma com validade nas duas instituições em que realizou suas pesquisas. As regras de formação das bancas de defesa e de apresentação dos trabalhos de conclusão também são diferenciadas na cotutela. A coorientação exige, em regra, apenas a participação de um docente externo na atividade de orientação do aluno" (MARRARA, 2007, p. 248).

2 A autorização, o reconhecimento e a renovação de reconhecimento de cursos de pós-graduação stricto sensu são concedidos pelo MEC, com base em parecer do Conselho Nacional de Educação, fundamentado nos resultados da avaliação quadrienal realizada pela Capes. Os PPGs avaliados recebem uma nota final na escala de "1" a "7", com base em conceitos atribuídos (Muito Bom, Bom, Regular, Fraco e Insuficiente) a cada item que compõe a ficha de avaliação (BRASIL, 2017b).

Recebido em: 16/12/2019.

Aprovado em: 19/12/2019.

Publicado em: 30/01/2020.

\section{Endereço para correspondência}

Jane Cruz Prates

Pontifícia Universidade Católica do Rio Grande do Sul

Av. Ipiranga, 6681, prédio 8, sala 403 - Partenon,

90619-900, Porto Alegre, RS, Brasil

\section{Autora:}

JANE CRuz PRATES

Doutora em Serviço Social pelo Programa de Pós-Graduação em Serviço Social (PPGSS/PUCRS), Porto Alegre, RS, Brasil.

Professora e Coordenadora do Programa de Pós-Graduação em Serviço Social da (PPGSS/PUCRS). Editora da revista Textos \& Contextos (Porto Alegre).

Orcid: https://orcid.org/0000-0003-0539-3600

E-mail: jprates@pucrs.br 